\title{
Multiple isoforms of both HSP70 and HSP90 families required for betanodavirus multiplication in medaka cells
}

Yasushi Okinaka ( $\square$ okinaka@hiroshima-u.ac.jp)

Hiroshima University https://orcid.org/0000-0002-8180-9105

Kosuke Zenke

Musashino University: Musashino Daigaku

\section{Research Article}

Keywords: heat shock protein, betanodavirus, host factor, medaka, isoform, model animal

Posted Date: March 3rd, 2022

DOI: https://doi.org/10.21203/rs.3.rs-1401847/v1

License: (a) (1) This work is licensed under a Creative Commons Attribution 4.0 International License. Read Full License 


\section{Abstract}

Heat shock proteins (HSPs) are molecular chaperones and have recently been revealed to function as host factors (HFs) for virus multiplication in fish as well as in mammals, plants, and insects. HSPs are classified into some families and have some isoforms in each family. However, no comprehensive studies were performed to clarify the biological importance of multiple isoforms in a certain HSP family for fish virus multiplication. Betanodaviruses are the causative agents of viral nervous necrosis in cultured marine fish and cause very high mortality. Although the viral genome and encoded proteins have been characterized extensively, information on HFs for the virus is limited. In this study, therefore, we focused on HSP70 and HSP90 families to examine the importance of many isoforms in the families for betanodavirus multiplication. We found that HSP inhibitors (17$A A G$, radicicol, and quercetin) suppressed viral RNA replication and production of progeny virus in infected medaka (Oryzias latipes) cells. A thermal stress or virus infection up-regulated the expression of some isoform genes and facilitated virus multiplication. Furthermore, overexpression and knockdown of some isoform genes revealed that HSP70-1, HSP70-2, HSP70-5, HSP90-a1, HSP90- $\alpha 2$, and HSP90- $\beta$ isoforms played positive roles in virus multiplication in medaka. Collectively, these results suggest that not a few isoforms in fish HPS families serve as HFs for betanodavirus multiplication.

\section{Introduction}

Any viruses require host cell factors for their multiplication. The roles of such host factors (HFs) for virus multiplication have been investigated thoroughly in mammals, insects, and plants. Identification of HFs is important not only for understanding basic mechanisms underlying virus multiplication but also for therapeutics, in which HFs are attractive targets to develop antiviral agents [1-3]. Over the past decade, an increasing number of HFs for fish viruses have been identified. One research trend of fish HFs is the discovery of defense-related factors, many of which are involved in the interferon system. They are categorized into positive [e. g., 4-10] and negative [e. g., 11-15] regulators for fish virus multiplication. Another research trend is the identification of heat shock proteins (HSPs) as fish HFs. Similar to the defense-related factors mentioned above, HSP HFs can be classified into two groups: facilitators [e. g., 16-20] and inhibitory factors [21, 22] for virus multiplication. The identification of the several HSPs as fish HFs is not surprising because in mammals, plants, and insects, many HSPs have been known as HFs for relevant viruses [23, 24]. HSPs comprise a large family of proteins and are known to function as molecular chaperones which are required for correct protein folding and intracellular transport both in prokaryotic and eukaryotic cells [25]. HSPs are classified into some families (e. g., HSP60, HSP70, HSP90) according to their molecular weight, and have some isoforms in each family [26]. However, many of the HSP studies for fish HFs were conducted without specifying which isoform was being studied [16-18, 20,27]. In addition, although there are several studies of HFs targeting specific isoforms of fish HSPs [22, 28-31], no comprehensive studies were performed to clarify the biological importance of more than one isoforms in a certain HSP family. In this study, we focused on HSP70 and HSP90 families in fish and examined the importance of many isoforms in these families as HFs. In order to improve the efficiency of the study, we used a betanodavirus, a model fish virus, and medaka (Oryzias latipes), a model fish, for the study.

Betanodaviruses are the causative agents of viral nervous necrosis of marine fish [32] and belong to the family Nodaviridae. Betanodaviruses are small in size [33] and possess a bipartite positive-sense RNA genome, the genome size of which is the smallest among fish viruses thus far identified [34,35]. The larger genomic RNA 
(RNA1) is $3.1 \mathrm{~kb}$ in length and encodes an RNA dependent RNA polymerase (protein A) while the smaller one (RNA2) is $1.4 \mathrm{~kb}$ and encodes a coat protein. The sub-genomic RNA3, transcribed from RNA1, is $0.4 \mathrm{~kb}$ which encodes a suppressor for post-transcriptional gene silencing (protein B2) [36,37] and an anti-necrotic death factor (protein B1) [38]. The virus can be classified into four genotypes, designated redspotted grouper nervous necrosis virus (RGNNV), striped jack nervous necrosis virus (SJNNV), barfin flounder nervous necrosis virus, and tiger puffer nervous necrosis virus, based on similarities in RNA2 sequences [39, 40]. The biological importance of the viral RNAs and encoded proteins were studied extensively [37, 41-45] using the reverse genetic technology based on a cDNA-mediated infectious RNA transcription strategy [46]. Recently, we established an experimental infection system of betanodaviruses using the model fish, medaka and its cell lines $[47,48]$.

On the other hand, medaka is an excellent vertebrate model used in various study areas including development, genetics, environmental toxicology and human disease [49-51]. In addition to preferable characteristics as a model animal such as small body size, high fecundity, tolerance to a wide range of environmental conditions, and easiness to rear, the availability of several inbred lines and enormous genetic diversity between those lines [52] are distinct features of medaka not found in other model fish species. Moreover, whole genomic sequencing [53] as well as the establishment of transgenesis and mutagenesis systems was completed in medaka [54-56].

In this study, we performed overexpression and knockdown experiments on many genes of HSP70 and HSP90 isoforms in medaka to evaluate their importance in betanodavirus multiplication. We also examined the inducibility of these isoforms by heat shock or virus infection stress. The elucidation of the isoforms involved or not in virus multiplication should not only help us to understand the mechanism of virus infection, but also provide important information for the development of specific antiviral drugs targeting specific HSP isoforms.

\section{Materials And Methods}

\section{Cells and virus}

The medaka cell line OLHNI-2 [57] was provided from $\mathrm{H}$. Mitani and cultured at $30^{\circ} \mathrm{C}$ in Leibovitz's L-15 medium (Thermo Fisher Scientific, Waltham, MA, USA) supplemented with 15\% fetal bovine serum (FBS) (Nichirei Biosciences, Tokyo, Japan). E-11 cells [58] were cultured at $25^{\circ} \mathrm{C}$ in L-15 medium supplemented with $5 \%$ FBS. The betanodavirus used in this study was RGNNV (SGWak97 strain) [59]. The virus was prepared from the OLHNI-2 cells transfected with in vitro transcribed viral RNAs according to the procedure described previously [43]. The RNA sequences of the obtained progeny virus were verified as described previously [43]. Viral titers were determined based on the $\mathrm{TCID}_{50}$ method [60] using E-11 cells.

\section{Plasmids}

The mRNA sequences of the five HSP70 isoforms (HSP70-1, HSP70-2, HSP70-5, HSP70-8, HSP70-9) and the five HSP90 isoforms (HSP90-a1, HSP90-a2, HSP90- $\beta$, GRP94, TRAP1) of medaka were retrieved from Ensemble Genome Browser (http://www.ensembl.org/index.html) and NBRP medaka (http://www.shigen.nig.ac.jp/medaka/). The nomenclature of HSPs in the present study was according to the guidelines of Kampinga et al [26] and Tavaria et al [61]. Based on the mRNA sequences obtained, the specific primers (Table 1) were designed to amplify DNA that encodes each of the HSP isoforms fused with the HA tag at the $\mathrm{N}$ - or $\mathrm{C}$-terminus. PCR was performed using the primers and cDNA prepared from mRNA of the medaka 
strain Cab. Amplified fragments were digested with $\mathrm{Xbal}$ and cloned into the $\mathrm{Xbal}$ site of the $\mathrm{pCl}$-Neo expression vector (Promega, Madison, WI, USA). The sequence integrity of all the constructs was verified by DNA sequencing using BigDye Terminator v1.1 Cycle Sequencing Kit and Applied Byosystems 3130xl genetic analyzer (Thermo Fisher Scientific). 
Table 1

Oligonucleotides used in the present study

\section{Name Sequence ${ }^{a}$ ( $5^{\prime}$ to $\left.3^{\prime}\right)$}

Primers for plasmid vector construction

HSP70- AGAGAG TCTAGAATGGGCTACCCATACGATGTTCCAGATTACGCGTCTGCGGCCAAGAGCGTG $1-\mathrm{pCl} \mathrm{F}$

HSP70- AGAGAG TCTAGATCAGTCCACCTCCTCAATAGTG $1-\mathrm{pCI} R$

HSP70- $\quad$ AGAGAG TCTAGAATGGGCTACCCATACGATGTTCCAGATTACGCG

2-pCI F GATACAGCAAAGGGAGTTTCCATT

HSP70- AGAGAG TCTAGACTAGTCCACTTCCTCTATGGTT

2-pCI R

HSP70- AGAGAG TCTAGAATGGGCAAGCTCTTGTGGGTGGTAATG

5-pCI F

HSP70- AGAGAG TCTAGACTACGCGTAATCTGGAACATCGTATGGGTATAATTCATCCTTCTCTGCC 5-pCl R

HSP70- AGAGAG TCTAGAATGGGCTACCCATACGATGTTCCAGATTACGCGTCTAAGGGACCAGCAGTCG

8-pCl F

HSP70- $\quad$ AGAGAG TCTAGATTAATCAACTTCTTCAATGGTTGG

8-pCl R

HSP70- AGAGAG TCTAGAATGGGCTACCCATACGATGTTCCAGATTACGCGTTGAGCGCTGCTAGAACCATTTC 9-pCl F

HSP70- AGAGAGTCTAGATTACTGCTGACCCTCCTTCTT

9-pCl R

HSP90- AGAGAG TCTAGAatgGGCtacccatacgatgttccagattacgcgCCAGAGAATGCTGCACATGTCA a1-pCl

$\mathrm{F}$

HSP90- AGAGAG TCTAGATTAGTCAACTTCTTCCATTCTTG

a1-pCl

$\mathrm{R}$

HSP90- AGAGAG TCTAGAatgGGCtacccatacgatgttccagattacgcgCCTGAGATGCATGACCAACCAAT a2-pCl

$\mathrm{F}$

HSP90- AGAGAG TCTAGATCAGTCCACCTCCTCCATTCTGGA

a2-pCl

$\mathrm{R}$

HSP90- AGAGAG TCTAGAatgGGCtacccatacgatgttccagattacgcgCCTGAAGAAATGCACCAAGAGGA $\beta$-pCl F

HSP90- AGAGAG TCTAGATTAGTCGACCTCTTCCATGCGTGA

$\beta-p C I R$

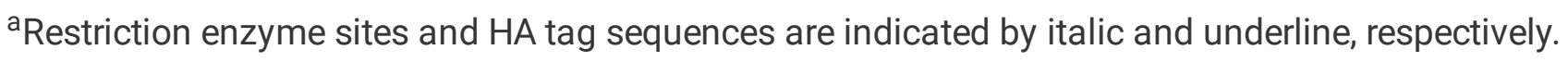




\section{Name Sequence ${ }^{\mathrm{a}}\left(5^{\prime}\right.$ to $\left.3^{\prime}\right)$}

GRP94- AGAGAGTCTAGAATGAAACGGCTGTGGGTGG

$\mathrm{pCl} \mathrm{F}$

GRP94- AGAGAG TCTAGACTACGCGTAATCTGGAACATCGTATGGGTACGAAACATTTGCTCCATGCCT

$\mathrm{pCl} R$

TRAP1- AGAGAGTCTAGAATGTCGCTTCCACTTGCTAGAG

$\mathrm{pCl} \mathrm{F}$

TRAP1- AGAGAGTCTAGACTACGCGTAATCTGGAACATCGTATGGGTAGTGTTTCTCCAGAGCCTT

$\mathrm{pCl} R$

Detection primers for quantitative real time RT-PCR

HSP70- AGAGGCTGATTGGGCGGAGG

$1 \mathrm{~F}$

HSP70- GGCTTCCCTCCTTCTGAAAC

$1 \mathrm{R}$

HSP70- CAAACGTCTCATTGGAAGAAAC

$2 \mathrm{~F}$

HSP70- CTCTTCAGGATAGAAGGCTTTAG

$2 \mathrm{R}$

HSP70- CCGTCTGACACCTGAAGACA

$5 \mathrm{~F}$

HSP70- AGGCGTAGCTCTCCAATTCA

$5 \mathrm{R}$

HSP70- GAAGTACAAGGCAGAAGATGATG

$8 \mathrm{~F}$

HSP70- CTTCATCACTGATCTTGCCAGC

$8 \mathrm{R}$

HSP70- ACACCGAGTCCAAGATGGAG

$9 \mathrm{~F}$

HSP70- AGATGTCCCTGACCTTGGTG

$9 \mathrm{R}$

HSP90- ATGTCATGGAGGAGGAGGTG

a1 $\mathrm{F}$

HSP90- GGAGATGAGCTCTCGAAGGA

a1 $\mathrm{R}$

HSP90- GATCAGTCAGAATACCTGGAG

a2 $\mathrm{F}$

HSP90- TTGTCCTCGTCGTCACTCAC

a2 R

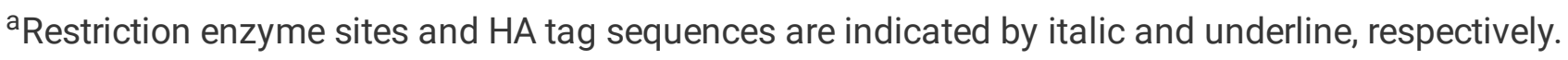




\begin{tabular}{|c|c|}
\hline Name & Sequence $^{\mathrm{a}}\left(5^{\prime}\right.$ to $\left.3^{\prime}\right)$ \\
\hline $\begin{array}{l}\text { HSP9O- } \\
\beta F\end{array}$ & GAGTACATTGAGGAGAAGAGG \\
\hline $\begin{array}{l}\text { HSP9O- } \\
\beta R\end{array}$ & TССТСАССTTССТССTTGG \\
\hline $\begin{array}{l}\text { GRP94 } \\
\text { F }\end{array}$ & GCCGACAAGGTCATCGTATC \\
\hline $\begin{array}{l}\text { GRP94 } \\
\text { R }\end{array}$ & GAGGCTTCCTCCTTCAGAAC \\
\hline $\begin{array}{l}\text { TRAP1 } \\
\text { F }\end{array}$ & TGTCGCTTCCACTTGCTAGA \\
\hline $\begin{array}{l}\text { TRAP1 } \\
\text { R }\end{array}$ & AGAAAGACTGCTGGCTCAGG \\
\hline $\begin{array}{l}\beta \text {-Actin } \\
\mathrm{F}\end{array}$ & GGGAGAAGATGACCCAGATC \\
\hline $\begin{array}{l}\text { B-Actin } \\
\mathrm{R}\end{array}$ & ACCAGAGTCCATGACGATAC \\
\hline
\end{tabular}

\section{Northern blot and Western blot analyses}

Total RNA and proteins were prepared from cells inoculated with RGNNV using the ISOGEN reagent (Nippon Gene, Tokyo, Japan) according to the manufacture's instructions. Total RNA was subjected to Northern blot analysis as described previously [46]. The coat protein in the protein samples extracted from equal number of cells was detected by Western blotting analysis as described previously [46] except in that a rabbit antiserum, raised against the recombinant RGNNV coat protein, was used as the primary antibody. All images of the blots were photographed by ChemiDoc XR system (Bio-Rad, Hercules, CA, USA) and quantitative data were obtained by analysis using Quantity One software (Bio-Rad).

\section{Treatments of cells with HSP inhibitors}

As HSP90 inhibitors, 17-(allylamino)-17-demethoxygeldanamycin (17-AAG) and radicicol were purchased from Wako Pure Chemical Industries (Osaka, Japan). Quercetin, which inhibits both HSP70 and HSP90, was purchased from the same company. All the chemicals were dissolved in dimethyl sulfoxide (DMSO) as the stock solutions ( $5 \mathrm{mM}$ for 17-AAG and radiciol, $20 \mathrm{mM}$ for quercetin) and stored at $-20^{\circ} \mathrm{C}$ until use.

OLHNI-2 cells seeded on a 24-well culture plate (Sumitomo Bakelite, Tokyo, Japan) at the density of $0.5 \times 10^{6}$ cells per well were cultured for $16 \mathrm{~h}$ at $30^{\circ} \mathrm{C}$. Cells then were inoculated with RGNNV at a multiplicity of infection (MOI) of 1.0 for 30 min and further cultured with medium containing the HSP inhibitors. Control cells were incubated with medium containing the same amount of DMSO. At $12 \mathrm{~h}$ post virus inoculation, the culture supernatants were collected and virus particles were purified using the PEG precipitation method [62] to remove the inhibitors from the samples. Viral titers of the samples thus obtained were determined as described earlier. 
Total RNA and proteins were also isolated from cells in replicated wells and subjected to Northern blot and Western blot analyses as described earlier. In order to assess the cytotoxic effects of the inhibitors, OLHNI-2 cells were seeded on a 96-well culture plate (Iwaki, Shizuoka, Japan) at the density of $0.5 \times 10^{5}$ cells per well. The cells then were cultured with the medium containing each of the inhibitors and cell viability was determined periodically using WST-1 Cell Proliferation Assay kit (Roche Diagnostics, Basel, Switzerland) according to the manufacture's recommendations.

\section{Thermal stress on the cells}

OLHNI-2 cells were seeded on a 6 -well culture plate (Sumitomo Bakelite) at the density of $1.0 \times 10^{6}$ cells per well and cultured for $16 \mathrm{~h}$ at $30^{\circ} \mathrm{C}$. Cells then were thermally stressed by submerging the culture plate in water at $42^{\circ} \mathrm{C}$ for $1 \mathrm{~h}$ and recovered at $30^{\circ} \mathrm{C}$ for $1 \mathrm{~h}$. The time point when recovery was finished was designated as $0 \mathrm{~h}$ after thermal stress. The cytotoxic effect of thermal stress was assessed using WST-1 Cell Proliferation Assay kit according to the manufacture's recommendations.

\section{Overexpression of the HSP genes}

OLHNI-2 cells were transfected with the plasmid encoding each of the HSP70 and HSP90 isoforms using Lullaby Transfection Reagent (OZ Biosciences, Marseille, France) according to the procedure recommended by the manufacturer with some modifications. Briefly, $500 \mathrm{ng}$ of plasmid DNA and $1 \mu$ Lullaby Transfection Reagent were diluted separately in $50 \mu \mathrm{l}$ Opti-MEM-I (Thermo Fisher Scientific). The diluted plasmid DNA and the transfection reagent then were combined and incubated for $20 \mathrm{~min}$ at room temperature. Finally, the transfection complex was combined with $400 \mu \mathrm{l}$ cell suspensions $\left(5 \times 10^{5} \mathrm{cell} / \mathrm{s} / \mathrm{ml}\right)$, plated on a 24 -well cell culture plate (Sumitomo Bakelite) and cultured for $48 \mathrm{~h}$. Transfected cells then were provided for virus inoculation.

\section{Knock down of the HSP genes}

siRNAs targeting each of the medaka HSP70 and HSP90 isoforms were designed using BLOCK-iT RNAi Designer with Stealth modification and purchased from Thermo Fisher Scientific. The Stealth modification is the chemical modification to siRNA, which enhances the potency and stability of siRNA as well as reduces the occurrence of the off-target effect. The target sequences of the siRNAs are listed in Table 2. Stealth RNAi GFP reporter control (Thermo Fisher Scientific), which targets the enhanced green florescent protein (EGFP) gene, was used as the control siRNA (siREGFP). OLHNI-2 cells were transfected with each of the siRNAs using X-treme gene siRNA transfection reagent (Roche Diagnostics) according to the manufacturer's instructions. Total RNA was isolated from cells in replicated wells at $48 \mathrm{~h}$ after transfection and target mRNAs in the samples were quantified by real time RT-PCR as described later. Cells at $48 \mathrm{~h}$ after transfection were also provided for virus inoculation. 
Table 2

siRNAs used in the present study

\begin{tabular}{|lll|}
\hline siRNA & Location $^{\text {a }}$ & Sequence (5' to $\mathbf{3}^{\prime}$ ) \\
\hline siRHSP70-1 & $1766-1790$ & CCGACAAAGACGAGTTCCAGCACAA \\
\hline siRHSP70-2 & $786-810$ & GAGGAGACTGAGAACGGCTTGTGAG \\
\hline siRHSP70-5 & $1578-1602$ & CGACCAGAACCGTCTGACACCTGAA \\
\hline siRHSP90-a1 & $213-228$ & GCTGAAGATTGAAGTCAGACCTGAT \\
\hline siRHSP90-a2 & $552-577$ & CCACCTGAAAGAAGATCAGTCAGAA \\
\hline siRHSP90- $\beta$ & $581-606$ & AGAAGAGGGTCAAAGAGATCGTGAA \\
\hline a Adenine residues of the start codons are designated as "1". \\
\hline
\end{tabular}

\section{Quantitative real time RT-PCR}

Total RNA was isolated from cells using the acid guanidinium thiocyanate-phenol-chloroform method [63] and treated with RQ1 RNase-free DNase (Promega), followed by purification using RNeasy mini RNA isolation kit (Qiagen, Venlo, Netherlands). To obtain cDNA, $0.5 \mu \mathrm{g}$ of the purified total RNA was incubated with $0.5 \mu \mathrm{l}$ of the oligo dT primer (20 $\mu \mathrm{M}$; Eurofins Genomics, Val Fleuri, Luxembourg) at $70^{\circ} \mathrm{C}$ for $10 \mathrm{~min}$ and further incubated at $42^{\circ} \mathrm{C}$ for 60 min supplemented with $2 \mu \mathrm{l} 5 \times \mathrm{RT}$ reaction buffer (Takara, Otsu, Japan), $2 \mu \mathrm{l}$ dNTP mix (2.5 mM each dNTP, Takara), 100 unit M-MLV reverse transcriptase (RNase H-, Takara), and 10 unit RNase inhibitor (Toyobo, Osaka, Japan) in a final reaction volume of $10 \mu \mathrm{l}$. The synthesized cDNA samples were diluted ten times with double-distilled water and stored at $-20^{\circ} \mathrm{C}$ until use.

Quantitative real time RT-PCR was performed using Thunderbird SYBR qPCR Mix (Toyobo) and Chromo4 RealTime PCR Detection System (Bio-Rad). The primer sets used to detect mRNAs of the HSP isoforms and $\beta$-actin are listed in Table 1. The reaction mixture for PCR contained $10 \mu$ l Thunderbird SYBR qPCR Mix, $0.5 \mu$ l each of the primers $(10 \mu \mathrm{M}), 3 \mu \mathrm{l}$ of the cDNA sample, and $6 \mu$ l double-distilled water. The amplification procedures included one cycle of $3 \mathrm{~min}$ at $95^{\circ} \mathrm{C}$, followed by 40 cycles of $30 \mathrm{sec}$ at $95^{\circ} \mathrm{C}$ and $30 \mathrm{sec}$ at $60^{\circ} \mathrm{C}$, with melting curve analysis. The relative mRNA expression was calculated by the standard curve method using the $\beta$-actin mRNA expression as the control for normalization.

\section{Immunocytochemistry}

Indirect immunofluorescence assay to detect HA-tagged HSP70 and HSP90 was performed as described previously with some modifications (Adachi et al, 2010). Briefly, cells were fixed with $4 \%$ paraformaldehyde and permeabilized by treatment with $0.1 \%$ NP-40 in PBS. The cells then were treated with a 1:500 dilution of anti-HA monoclonal antibody (Wako Pure Chemical Industries), followed by the treatment with a 1:2000 dilution of Alexa Fluor 555 goat anti-mouse IgG (Thermo Fisher Scientific). Cells were simultaneously stained with 4',6-diamidino2-phenylindole (DAPI) (Dojindo, Kumamoto, Japan) and were observed under the fluorescence microscope (ORCA-1394 and AQUA-Lite version 1.10 systems; Hamamatsu Photonics, Hamamatsu, Japan). 


\section{Results}

\section{Effects of the HSP inhibitors on virus multiplication in medaka cells}

To confirm whether medaka HSP70 and HSP90 include any HFs for RGNNV, we tested the effects of the three well-known chemical inhibitors for HSPs on virus multiplication in medaka cells. Although the concentrations of inhibitors used in this study ( $5 \mu \mathrm{M}$ for 17-AAG and radicicol, $25 \mu \mathrm{M}$ for quercetin) were suggested to be the most effective and the least toxic to the insect cells [64], a modest cytotoxic effect was observed in medaka cells at 24 post treatment with these inhibitors (Fig. 1A). Accordingly, hereafter, effects of these inhibitors were investigated within $12 \mathrm{~h}$ post treatment.

First, effects of these inhibitors on the production of progeny virus were examined. Viral titers in the supernatants at $12 \mathrm{~h}$ post virus inoculation were reduced by the ratio of $0.28,0.03$, and 0.07 in the cells treated with 17-AAG, radicicol, and quercetin, respectively, when compared with cells without any treatments (Fig. 1B). Slight reduction in viral titer was observed in control cells treated with vehicle only. To further elucidate the steps of virus multiplication affected by the HSP inhibitors, the viral RNA and protein were analyzed quantitatively by Northern blotting and Western blotting, respectively. Production of the viral RNA and protein was suppressed in cells treated with each of the inhibitors, the effect of which was the most significant in cells treated with radicicol (Fig. 1C, D). No obvious difference was found in replication competence between the positive and negative strand RNAs. Interestingly, the production of the coat protein was diminished by treatment with the inhibitors, the level of which was lower than that observed for RNA2 replication. These results suggest that inhibition of HSPs affected viral protein production as well as viral RNA replication. Alternatively, HSP inhibition might affect exclusively the production of viral proteins including protein $A$, which hence reduces viral RNA replication.

\section{Effect of the thermal stress on virus multiplication}

Since the inhibition of HSPs activity suppressed virus multiplication, we next examined the effect of artificial induction of HSPs on virus multiplication by subjecting cells to non-lethal thermal stress. We found that the treatment of cells at $42^{\circ} \mathrm{C}$ for $1 \mathrm{~h}$ was the minimum requirement to up-regulate HSPs (data not shown) though a slight cytotoxic effect on the cells was also observed at $12 \mathrm{~h}$ after the treatment (Fig. 2A). When cells were inoculated with RGNNV immediately after the thermal stress, from 4.64 to 6.12 times more progeny virus was produced compared with control cells (Fig. 2B). Similarly, production of the viral RNA and protein was increased by the heat treatment (Fig. 2D, E). On the other hand, when cells were inoculated with RGNNV at $12 \mathrm{~h}$ after the thermal stress, from 1.45 to 2.82 times more virus was produced (Fig. 2C).

We examined the effect of the thermal stress on the expression of major HSP70 isoforms (HSP70-1, HSP70-2, HSP70-5, HSP70-8, HSP70-9) and all of the HSP90 isoforms (HSP90-a1, HSP90-a2, HSP90- $\beta$, GRP94, TRAP1) of medaka. Among the ten HSPs tested, HSP70-1, HSP70-2, HSP70-5, HSP90-a1, and HSP90-a2 was greatly upregulated immediately after the thermal stress (Fig. 3). The up-regulation of HSP70-2 and HSP90-a2 was sustained at least for $48 \mathrm{~h}$ post thermal stress while the expression of HSP70-1 and HSP90-a1 was returned to the control level at $48 \mathrm{~h}$ post thermal stress. The up-regulation of HSP70-5 was observed only immediately after the thermal stress and then down-regulated to basal level at $12 \mathrm{~h}$ post thermal stress. 


\section{Effect of the virus infection on the expression of the HSP70 and HSP90 isoforms}

We next examined whether virus infection itself induces the expression of the HSPs. Among the ten HSP isoforms tested, HSP70-1, HSP70-2, HSP90-a1, and HSP90-a2 were up-regulated strongly by virus infection and the levels were increased with time (Fig. 4). In contrast, no up-regulation was observed for HSP70-5, HSP70-9, GRP94, or TRAP1. HSP70-8 and HSP90- $\beta$ were slightly up-regulated at $6 \mathrm{~h}$ post virus infection (Fig. 4). Nevertheless, the levels of up-regulation by virus infection were relatively low compared with those obtained after the thermal stress (Fig. 3).

\section{Effects of overexpression of the HSP isoform genes on virus multiplication}

In order to identify the HSP isoforms which support virus multiplication, we overexpressed each of the ten HSP isoforms in medaka cells prior to virus inoculation. HA-tagged HSPs were successfully expressed in cells transfected with each of the expression vectors (Fig. 5A). When compared with the control, the levels of virus multiplication were elevated in cells transfected with the vector expressing HSP70-1, HSP70-2, HSP70-5, HSP90a1, HSP90-a2, or HSP90- $\beta$ (Fig. 5B). While the levels of virus multiplication were reduced to less than those of the control when cells were transfected with the vector expressing HSP70-8, HSP70-9, GRP94, or TRAP1. These results suggest that HSP70-1, HSP70-2, HSP70-5, HSP90- $\alpha 1$, HSP90- $\alpha 2$, and HSP90- $\beta$ serve as positive factors for betanodavirus multiplication. Conversely, HSP70-8, HSP70-9, GRP94, and TRAP1 might function as negative components.

\section{Effects of knockdown of the HSP isoform genes on virus multiplication}

Based on the results of the overexpression experiments, we further examined the positive roles of HSP70-1, HSP70-2, HSP70-5, HSP90- 1 1, HSP90- $\alpha 2$, and HSP90- $\beta$ in virus multiplication via knockdown experiments. The treatments of siRNAs, targeting HSP70-1, HSP70-2, HSP70-5, HSP90- 1 1, HSP90- $\alpha 2$, and HSP90- $\beta$, reduced successfully the expression levels of corresponding mRNA to $42.1,46.2,49.7,48.5,42.7$, and $38.9 \%$ of the control level, respectively (Fig. 6A). When the cells, transfected with each of the six siRNAs, were inoculated with RGNNV, progeny virus was decreased in all the treatments compared to the control (Fig. 6B).

\section{Discussion}

Non-lethal stressors including thermal stresses activated the synthesis of HSPs and protected fish from bacterial infections $[65,66]$. For example, treatments of the chemical compound TEX-OE and its variant induced HSPs non-lethally in salmon and gilthead sea bream (Sparus aurata), which protected these fish species from Vibrio anguillarum infection [66]. Bacterial infections up-regulated HSP70 in rainbow trout (Oncorhynchus mykiss) and sea bream (Sparus sarba), which were suggested as defense responses of the hosts against the bacterial pathogens [67-71]. However, these inhibitory functions of HSPs in bacterial infections are not necessarily true for viral infections. Relatively more fish HSPs are thus far described as positive HFs for the relevant viruses [e. g., 16-20] compared to those designated as negative factors [21, 22]. As for HSPs involved in 
betanodavirus infection, HSP70-5 supports RGNNV multiplication in the grouper (Epinephelus coioides) cells GF1 [29] and HSP90- $\beta$ also serves as a positive HF for the virus in GF-1 cells [72] and in the marine medaka (Oryzia melastigma) cells hMMES1 [31], which are consistent with our overexpression and knockdown experiments using OLHNI-2 cells (Figs. 5 and 6). In contrast, HSP27 in sea perch (Lateolabrax japonicus) exerts anti-RGNNV activities by regulating the apoptosis signaling pathway [21]. In the present study, HSP70-1, HSP70-2, HSP90-a1, and HSP90- $\alpha 2$ as well as HSP70-5 and HSP90- $\beta$ facilitated RGNNV multiplication in medaka cells (Figs. 5 and 6). In contrast, HSP70-8, HSP70-9, GRP94, and TRAP1 suppressed virus multiplication though further studies including knockdown each of the four genes are required to confirm this activity. One curious observation is that overexpression of HSP70-8 suppressed RGNNV multiplication in medaka cells, which is apparently contradict to the precedent report by Chang and Chi [28]. A possible explanation for the discrepancy is that our data were obtained using OLHNI-2 cells derived from medaka, the host specificity of which is different from that of grouper used by Chang and Chi [28]. Medaka is susceptible to SJNNV as well as RGNNV though the levels of SJNNV infections are less than those of RGNNV infections [48]. Conversely, groupers are susceptible to RGNNV but entirely resistant to SJNNV $[42,43]$. Chang and Chi [28] indicated that HSP70-8 functions as an RGNNV receptor or coreceptor which probably distinguishes the difference between SJNNV and RGNNV. Therefore, some protein other than HSP70-8 might function as a RGNNV receptor in medaka. In any event, more studies are required to know the whole picture of HSP isoforms involved in fish virus multiplication.

Among the three inhibitors used in this study, radicicol and 17-AAG inhibit specifically HSP90 activity through the inhibition of ATP binding to HSP90 [73]. Quercetin inhibits the activity of the transcription factor, heat shock factor 1, resulting in down-regulation of broader members of HSPs including HSP70 and HSP90 [74, 75]. In this study, radicicol, 17-AAG, and quercetin had inhibitory effects on the RNA replication and progeny virus production of RGNNV (Fig. 1). These results are consistent with the previous studies that the treatment of the marine medaka cells hMMES1 with ganetespib or NVP-AUY922, the inhibitors of HSP90ab1, significantly decreased RGNNV entry into the cells [31]. Furthermore, geldanamycin (GA, a prototype of 17-AAG) and radicicol negatively affected the replicative and multiplicative competence of frock house virus (FHV) belonging to the same family Nodaviridae as RGNNV [64]. Similar negative effects of the HSP inhibitors were found for other virus species such as hepatitis viruses [76-79], influenza virus [80], Ebola virus [81], and herpes simplex virus [51]. However, in contrast, the treatment of GF-1 cells with GA facilitated the multiplication of RGNNV [72]. One possible reason for these contradictory findings is the difference in the dose of inhibitors used. While we treated the $5 \mu \mathrm{M}$ concentration of 17-AAG, Chen et al [72] used the relatively low concentration of GA (1.5 uM). Since inhibition of HSP90 by GA is known to trigger simultaneously up-regulation of HSP90 [82], the concentration of GA used by Chen et al [72] might be sufficient to up-regulate HSP90 but not to inhibit HSP90 activity. Alternatively, a treatment of GF-1 cells with GA could give some unexpected effects on virus multiplication. Although the cytotoxic effect of GA on GF-1 cells was not tested by Chen et al [72], we confirmed that GA gave a harmful effect on medaka cells at the concentration of as little as $1 \mu \mathrm{M}$ within $12 \mathrm{~h}$, which prompted us to use 17-AAG instead of GA in this study.

In this study, overexpression and knockdown experiments on the HSP70 and HSP90 isoforms revealed that HSP70-1, HSP70-2, HSP70-5, Hso90-a1, Hso90-a2, and HSP90- $\beta$ facilitated virus multiplication. Overexpression of these six isoforms increased the levels of viral multiplication from 1.69 to 3.63 times more than that of the control (Fig. 5B). However, the increasing rates were less than those observed in the previous study [29]. One possible explanation for this discrepancy is that the expression levels of the exogenous HSP genes were not

Page $12 / 26$ 
high enough to give good increasing rates in viral titer in this study because of the low transfection efficiencies (Fig. 5A). Similarly, knockdown of the endogenous genes encoding the six HSP isoforms decreased the levels of viral multiplication at the rates from 0.26 to 0.55 of that of the control (Fig. 6B), which is less efficient than the previous results reported by Su et al [29]. Since the knockdown levels of the isoform mRNAs obtained in this study were around $40 \%$ of the control (Fig. 6A), more efficient knockdown of the HSPs should impair more efficiently virus multiplication.

We showed that HSP70-1, HSP70-2, HSP70-5, HSP90-a1, HSP90-a2, and HSP90- $\beta$ played positive roles for betanodavirus multiplication. Surprisingly, all of these but HSP70-5 were up-regulated by virus infection exclusively among the ten HSP isoforms tested, though the ten HSP isoforms are known to be up-regulated by various physiological or pathological stimuli in human [26, 61, 82]. Su et al [29] reported that up-regulation of HSP70-5 occurred in GF-1 cells at 48 and $72 \mathrm{~h}$ post inoculation with RGNNV $(\mathrm{MOI}=5)$. We could not examine the expression of HSP70-5 in medaka cells at $48 \mathrm{~h}$ post inoculation because almost all of the cells were disrupted by a cytopathic effect at this period (data not shown). HSP90- $\beta$ in GF-1 cells was up-regulated by inoculation with RGNNV $(\mathrm{MOI}=0.1)$ at as early as $6 \mathrm{~h}$ post inoculation [72], which is well consistent with our data that HSP90- $\beta$ was up-regulated in medaka cells at $6 \mathrm{~h}$ post RGNNV inoculation (Fig. 4). Collectively, these results imply that RGNNV actively induces those six HSP isoforms to facilitate its multiplication. The viral manipulation of host cells via alteration of the gene expression has been reported in various virus species [83-86].

Nevertheless, we still can not rule out the possibility that induction of some or all of the virologically important HSP isoforms were just results of host stress responses against virus infection and were incidentally utilized for virus multiplication.

\section{Declarations}

\section{Acknowledgements}

We would like to thank Dr. H. Mitani, The University of Tokyo, for providing the medaka cell lines. This work was supported in part by a grant-in-aid for the Program for Promotion of Basic and Applied Researches for Innovations in Bio-oriented Industry (BRAIN) and by a grant-in-aid for Scientific Research (20380111) from the Ministry of Education, Culture, Sports, Science and Technology, Japan.

\section{Author contributions}

KZ performed the experiments and prepared the manuscript. YO prepared the manuscript and supervised the experiments described in the article.

\section{Compliance with Ethical Standards}

\section{Disclosure of potential conflicts of interest:}

All authors declare no conflict of interest.

\section{Research involving Human Participants and/or Animals:}

No humans or animals were used in this study. 


\section{Informed consent:}

All authors approved the final draft.

\section{Funding:}

This work was supported in part by a grant-in-aid for the Program for Promotion of Basic and Applied Researches for Innovations in Bio-oriented Industry (BRAIN) and by a grant-in-aid for Scientific Research (20380111) from the Ministry of Education, Culture, Sports, Science and Technology, Japan.

\section{References}

1. Jahanafrooz Z, Chen Z, Bao J, Li H, Lipworth L, Guo X (2022) An overview of human proteins and genes involved in SARS-CoV-2 infection. Gene 808:145963

2. Shukla E, Chauhan R (2019) Host-HIV-1 Interactome: A quest for novel therapeutic intervention. Cells 8:1155

3. Söderholm S, Fu Y, Gaelings L, Belanov S, Yetukuri L, Berlinkov M, Cheltsov AV, Anders S, Aittokallio T, Nyman TA, Matikainen S, Kainov DE (2016) Multi-omics studies towards novel modulators of influenza A virus-host interaction. Viruses 8:269

4. Huang R, Zhu G, Zhang J, Lai Y, Xu Y, He J, Xie J (2017) Betanodavirus-like particles enter host cells via clathrin-mediated endocytosis in a cholesterol-, pH- and cytoskeleton-dependent manner. Vet Res 48:8

5. Liu X, Qin Z, Babu VS, Zhao L, Li J, Zhang X, Lin L (2019) Transcriptomic profiles of striped snakehead cells (SSN-1) infected with snakehead vesiculovirus (SHVV) identifying IFI35 as a positive factor for SHVV replication. Fish Shellfish Immunol 86:46-52

6. Lu LF, Zhang C, Li ZC, Zhou XY, Jiang JY, Chen DD, Zhang YA, Xiong F, Zhou F, Li S (2021) A novel role of Zebrafish TMEM33 in negative regulation of interferon production by two distinct mechanisms. PloS Pathog 17:e1009317

7. Rao Y, Ji J, Liao Z, Su H, Su J (2019) GCRV hijacks TBK1 to evade IRF7-mediated antiviral immune responses in grass carp Ctenopharyngodon idella. Fish Shellfish Immunol 93:492-499

8. Sun M, Wu S, Zhang X, Zhang L, Kang S, Qin Q, Wei J (2021) Grouper TRAF5 exerts negative regulation on antiviral immune response against iridovirus. Fish Shellfish Immunol 115:7-13

9. Xu TJ, Chu Q, Cui JX (2018) Rhabdovirus-inducible microRNA-210 modulates antiviral innate immune response via targeting STING/MITA in fish. J Immunol 201:982-994

10. Yu Y, Li C, Wang Y, Wang Q, Wang S, Wei S, Yang M, Qin Q (2019) Molecular cloning and characterization of grouper Krüppel-like factor 9 gene: Involvement in the fish immune response to viral infection. Fish Shellfish Immunol 89:677-686

11. Chen B, Huo S, Liu W, Wang F, Lu Y, Xu Z, Liu X (2019) Fish-specific finTRIM FTR36 triggers IFN pathway and mediates inhibition of viral replication. Fish Shellfish Immunol 84:876-884

12. Huang Y, Yu Y, Yang Y, Yang M, Zhou L, Huang X, Qin Q (2016) Antiviral function of grouper MDA5 against iridovirus and nodavirus. Fish Shellfish Immunol 54:188-196

13. Kim MS, Shin MJ, Kim KH (2018) Increase of viral hemorrhagic septicemia virus growth by knockout of IRF9 gene in Epithelioma papulosum cyprini cells. Fish Shellfish Immunol 83:443-448 
14. Wei M, Zhang Y, Aweya JJ, Wang F, Li S, Lun J, Zhu C, Yao D (2019) Litopenaeus vannamei Src64B restricts white spot syndrome virus replication by modulating apoptosis. Fish Shellfish Immunol 93:313-321

15. Zhang Y, Huang L, Gao X, Qin Q, Huang X, Huang Y (2022) Grouper USP12 exerts antiviral activity against nodavirus infection. Fish Shellfish Immunol 121:332-341

16. Chen HJ, Li PH, Yang Y, Xin XH, Ou Y, Wei JG, Huang YH, Huang XH, Qin QW, Sun HY (2021) Characterization and function analysis of Epinephelus coioides Hsp40 response to Vibrio alginolyticus and SGIV infection. Fish Shellfish Immunol 118:396-404

17. Li W, Yu F, Wang H, Hong X, Lu L (2020) Induction of pro-viral grass carp Ctenopharyngodon idella Hsp70 instead of Hsc70 during infection of grass carp reovirus. Fish Shellfish Immunol 98:1024-1029

18. Li PH, Cai YJ, Zhu XL, Yang JDH, Yang SQ, Huang W, Wei SN, Zhou S, Wei JG, Qin QW, Sun HY (2022) Epinephelus coioides Hsp27 negatively regulates innate immune response and apoptosis induced by Singapore grouper iridovirus (SGIV) infection. Fish Shellfish Immunol 120:470-480

19. Yu F, Wang L, Li W, Wang H, Que S, Lu L (2020) Aquareovirus NS31 protein serves as a specific inducer for host heat shock 70-kDa protein. J Gen Virol 101:144-155

20. Zhang Y, Zhang YA, Tu J (2021) Hsp90 is required for snakehead vesiculovirus replication via stabilization of the viral L protein. J Virol 95:e0059421

21. Le Y, Jia P, Jin Y, Liu W, Jia K, Yi M (2017) The antiviral role of heat shock protein 27 against red spotted grouper nervous necrosis virus infection in sea perch. Fish Shellfish Immunol 70:185-194

22. Li C, Shi L, Gao Y, Lu Y, Ye J, Liu X (2021) HSC70 inhibits spring viremia of carp virus replication by inducing MARCH8-mediated lysosomal degradation of G protein. Front Immunol 12:724403

23. Lubkowska A, Pluta W, Strońska A, Lalko A (2021) Role of heat shock proteins (HSP70 and HSP90) in viral infection. Int J Mol Sci 22:9366

24. Nagy PD, Wang RY, Pogany J, Hafren A, Makinen K (2011) Emerging picture of host chaperone and cyclophilin roles in RNA virus replication. Virology 411:374-382

25. Hartl FU, Hayer-Hartl M (2002) Molecular chaperones in the cytosol: from nascent chain to folded protein. Science 295:1852-1858

26. Kampinga HH, Hageman J, Vos MJ, Kubota H, Tanguay RM, Bruford EA, Cheetham ME, Chen B, Hightower LE (2009) Guidelines for the nomenclature of the human heat shock proteins. Cell Stress Chaperones $14: 105-111$

27. Pham PH, Sokeechand BSH, Hamilton ME, Misk E, Jones G, Lee LEJ, Lumsden JS, Bols NC (2019) VER155008 induced Hsp70 proteins expression in fish cell cultures while impeding replication of two RNA viruses. Antiviral Res 162:151-162

28. Chang JS, Chi SC (2015) GHSC70 is involved in the cellular entry of nervous necrosis virus. J Virol 89:6170

29. Su YC, Wu JL, Hong JR (2011) Betanodavirus up-regulates chaperone GRP78 via ER stress: roles of GRP78 in viral replication and host mitochondria-mediated cell death. Apoptosis 16:272-287

30. Xu H, Yan F, Deng X, Wang J, Zou T, Ma X, Zhang X, Qi Y (2009) The interaction of white spot syndrome virus envelope protein VP28 with shrimp Hsc70 is specific and ATP-dependent. Fish Shellfish Immunol 26:414-421 
31. Zhang WW, Jia KT, Jia P, Xiang YX, Lu XB, Liu W, Yi M (2020) Marine medaka heat shock protein 90ab1 is a receptor for red-spotted grouper nervous necrosis virus and promotes virus internalization through clathrinmediated endocytosis. PLoS Pathog 16:e1008668

32. Bandín I, Souto S (2020) Betanodavirus and VER disease: A 30-year research review. Pathogens 9:106

33. Chen NC, Yoshimura M, Guan HH, Wang TY, Misumi Y, Lin CC, Chuankhayan P, Nakagawa A, Chan SI, Tsukihara T, Chen TY, Chen CJ (2015) Crystal structures of a piscine betanodavirus: mechanisms of capsid assembly and viral infection. PLoS Pathog 11:e1005203

34. Mori K, Nakai T, Muroga K, Arimoto M, Mushiake K, Furusawa I (1992) Properties of a new virus belonging to nodaviridae found in larval striped jack (Pseudocaranx dentex) with nervous necrosis. Virology 187:368371

35. Schneemann A, Ball AL, Delsert C, Johnson JE, Nishizawa T (2005) Family Nodaviridae. p865-872. In: Fauquet CM, Mayo MA, Maniloff J, Desselberger U, Ball LA (eds) Virus taxonomy. Academic Press, San Diego, In

36. Fenner BJ, Thiagarajan R, Chua HK, Kwang J (2006) Betanodavirus B2 is an RNA interference antagonist that facilitates intracellular viral RNA accumulation. J Virol 80:85-94

37. Iwamoto T, Mise K, Takeda A, Okinaka Y, Mori K, Arimoto M, Okuno T, Nakai T (2005) Characterization of Striped jack nervous necrosis virus subgenomic RNA3 and biological activities of its encoded protein B2. J Gen Virol 86:2807-2816

38. Chen LJ, Su YC, Hong JR (2009) Betanodavirus non-structural protein B1: A novel anti-necrotic death factor that modulates cell death in early replication cycle in fish cells. Virology 385:444-454

39. Nishizawa T, Furuhashi M, Nagai T, Nakai T, Muroga K (1997) Genomic classification of fish nodaviruses by molecular phylogenetic analysis of the coat protein gene. Appl Environ Microbiol 63:1633-1636

40. Okinaka Y, Nakai T (2008) Comparisons among the complete genomes of four betanodavirus genotypes. Dis Aquat Org 80:113-121

41. Hata N, Okinaka Y, Iwamoto T, Kawato Y, Mori K, Nakai T (2010) Identification of RNA regions that determine temperature sensitivity in betanodaviruses. Arch Virol 155:1597-1606

42. Ito Y, Okinaka Y, Mori K, Sugaya T, Nishioka T, Oka M, Nakai T (2008) The variable region of RNA2 is sufficient to determine host specificity in betanodaviruses. Dis Aquat Org 79:199-205

43. Iwamoto T, Okinaka Y, Mise K, Mori K, Arimoto M, Okuno T, Nakai T (2004) Identification of host-specificity determinants in betanodaviruses by using reassortants between striped jack nervous necrosis virus and sevenband grouper nervous necrosis virus. J Virol 78:1256-1262

44. Souto S, Mérour E, Biacchesi S, Brémont M, Olveira JG, Bandín I (2015) In vitro and in vivo characterization of molecular determinants of virulence in reassortant betanodavirus. J Gen Virol 96:1287-1296

45. Souto S, Olveira JG, Dopazo CP, Borrego JJ, Bandín I (2018) Modification of betanodavirus virulence by substitutions in the 3' terminal region of RNA2. J Gen Virol 99:1210-1220

46. Iwamoto T, Mise K, Mori K, Arimoto M, Nakai T, Okuno T (2001) Establishment of an infectious RNA transcription system for Striped jack nervous necrosis virus, the type species of the betanodaviruses. J Gen Virol 82:2653-2662

47. Adachi K, Sumiyoshi K, Ariyasu R, Yamashita K, Zenke K, Okinaka Y (2010) Susceptibilities of medaka (Oryzias latipes) cell lines to a betanodavirus. Virol J 7:150 
48. Furusawa R, Okinaka Y, Nakai T (2006) Betanodavirus infection in the freshwater model fish medaka (Oryzias latipes). J Gen Virol 87:2333-2339

49. Ishikawa Y (2000) Medaka fish as a model system for vertebrate developmental genetics. BioEssays 22:487-495

50. Sasado T, Tanaka M, Kobayashi K, Sato T, Sakaizumi M, Naruse K (2010) The National BioResource Project Medaka (NBRP Medaka): an integrated bioresource for biological and biomedical sciences. Exp Anim 59:13-23

51. Wittbrodt J, Shima A, Schartl M (2002) Medaka-a model organism from the far East. Nat Rev Genet 3:5364

52. Matsumoto Y, Oota H, Asaoka Y, Nishina H, Watanabe K, Bujnicki JM, Oda S, Kawamura S, Mitani H (2009) Medaka: a promising model animal for comparative population genomics. BMC Res Notes 2:88

53. Kasahara M, Naruse K, Sasaki S, Nakatani Y, Qu W, Ahsan B, Yamada T, Nagayasu Y, Doi K, Kasai Y, Jindo T, Kobayashi D, Shimada A, Toyoda A, Kuroki Y, Fujiyama A, Sasaki T, Shimizu A, Asakawa S, Shimizu N, Hashimoto S, Yang J, Lee Y, Matsushima K, Sugano S, Sakaizumi M, Narita T, Ohishi K, Haga S, Ohta F, Nomoto H, Nogata K, Morishita T, Endo T, Shin-I T, Takeda H, Morishita S, Kohara Y (2007) The medaka draft genome and insights into vertebrate genome evolution. Nature 447:714-719

54. Grabher C, Wittbrodt J (2007) Meganuclease and transposon mediated transgenesis in medaka. Genome Biol 8:S10

55. Mitani H, Kamei Y, Fukamachi S, Od S, Sasaki T, Asakawa S, Todo T, Shimizu N (2006) The medaka genome: why we need multiple fish models in vertebrate functional genomics. Genome Dyn 2:165-182

56. Taniguchi Y, Takeda S, Furutani-Seiki M, Kamei Y, Todo T, Sasado T, Deguchi T, Kondoh H, Mudde J, Yamazoe M, Hidaka M, Mitani H, Toyoda A, Sakaki Y, Plasterk RH, Cuppen E (2006) Generation of medaka gene knockout models by target-selected mutagenesis. Genome Biol 7:R116

57. Hirayama M, Mitani H, Watabe S (2006) Temperature-dependent growth rates and gene expression patterns of various medaka Oryzias latipes cell lines derived from different populations. J Comp Physiol 176:311320

58. Iwamoto T, Nakai T, Mori K, Arimoto M, Furusawa I (2000) Cloning of the fish cell line SSN-1 for piscine nodaviruses. Dis Aquat Org 43:81-89

59. Iwamoto T, Mori K, Arimoto M, Nakai T (1999) High permissivity of the fish cell line SSN-1 for piscine nodaviruses. Dis Aquat Org 39:37-47

60. Reed LJ, Muench H (1938) A simple method of estimating fifty per cent endpoints. Am J Hyg 27:493-497

61. Tavaria M, Gabriele T, Kola I, Anderson RL (1996) A hitchhiker's guide to the human Hsp70 family. Cell Stress Chaperones 1:23-28

62. Arhel N, Kirchhoff F (2010) Host proteins involved in HIV infection: new therapeutic targets. Biochim Biophys Acta 1802:313-321

63. Chomczynski P, Sacchi N (1987) Single-step method of RNA isolation by acid guanidinium thiocyanatephenol-chloroform extraction. Anal Biochem 162:156-159

64. Kampmueller KM, Miller DJ (2005) The cellular chaperone heat shock protein 90 facilitates Flock House virus RNA replication in Drosophila cells. J Virol 79:6827-6837 
65. Sung YY, MacRae TH (2011) Heat shock proteins and disease control in aquatic organisms. J Aquac Res Development S2:006

66. Roberts RJ, Agius C, Saliba C, Bossier P, Sung YY (2010) Heat shock proteins (chaperones) in fish and shellfish and their potential role in relation to fish health: a review. J Fish Dis 33:789-801

67. Ackerman A, Iwama GK (2001) Physiological and cellular response of juvenile rainbow trout to vibriosis. J Aquat Anim Health 13:173-180

68. Cheng J, Li H, Huang Z, Zhang F, Bao L, Li Y, Chen L, Xue L, Chu W, Zhang J (2019) Expression analysis of the heat shock protein genes and cellular reaction in dojo loach (Misgurnus anguillicaudatus) under the different pathogenic invasion. Fish Shellfish Immunol 95:506-513

69. Deane EE, Li J, Woo NYS (2004) Modulated heat shock protein expression during pathogenic Vibrio alginolyticus stress of sea bream. Dis Aquat Org 62:205-215

70. Forsyth RB, Candido PM, Babich SL, Iwama GK (1997) Stress protein expression in coho salmon with bacterial kidney disease. J Aquat Anim Health 9:18-25

71. Yao L, Qu B, Ma Z, Chen Y, Tan Y, Gao Z, Zhang S (2019) Lectin-like and bacterial-agglutinating activities of heat shock proteins Hsp5 and Hsp90a from amphioxus Branchiostoma japonicum. Fish Shellfish Immunol 95:688-696

72. Chen YM, Kuo CE, Wang TY, Shie PS, Wang WC, Huang SL, Tsai TJ, Chen PP, Chen JC, Chen TY (2010) Cloning of an orange-spotted grouper Epinephelus coioides heat shock protein 90AB (HSP90AB) and characterization of its expression in response to nodavirus. Fish Shellfish Immunol 28:895-904

73. Hadden MK, Lubbers DJ, Blagg BS (2006) Geldanamycin, radicicol, and chimeric inhibitors of the Hsp90 Nterminal ATP binding site. Curr Top Med Chem 6:1173-1182

74. Aalinkeel R, Bindukumar B, Reynolds JL, Sykes DE, Mahajan SD, Chadha KC, Schwartz SA (2008) The dietary bioflavonoid, quercetin, selectively induces apoptosis of prostate cancer cells by down-regulating the expression of heat shock protein 90. Prostate 68:1773-1789

75. Hosokawa N, Hirayoshi K, Kudo H, Takechi H, Aoike A, Kawai K, Nagata K (1992) Inhibition of the activation of heat shock factor in vivo and in vitro by flavonoids. Mol Cell Biol 12:3490-3498

76. Gonzalez O, Fontanes V, Raychaudhuri S, Loo R, Loo J, Arumugaswami V, Sun R, Dasgupta A, French SW (2009) The heat shock protein inhibitor Quercetin attenuates hepatitis C virus production. Hepatology 50:1756-1764

77. Hu J, Seeger C (1996) Hsp90 is required for the activity of a hepatitis B virus reverse transcriptase. Proc Natl Acad Sci USA 93:1060-1064

78. Okamoto T, Nishimura Y, Ichimura T, Suzuki K, Miyamura T, Suzuki T, Moriishi K, Matsuura Y (2006) Hepatitis C virus RNA replication is regulated by FKBP8 and Hsp90. EMBO J 25:5015-5025

79. Wu X, Tao P, Nie H (2011) Geldanamycin is effective in the treatment of herpes simplex virus epithelial keratitis in a rabbit model. Clin Exp Ophthalmol 39:779-783

80. Chase G, Deng T, Fodor E, Leung BW, Mayer D, Schwemmle M, Brownlee G (2008) Hsp90 inhibitors reduce influenza virus replication in cell culture. Virology 377:431-439

81. Smith DR, McCarthy S, Chrovian A, Olinger G, Stossel A, Geisbert TW, Hensley LE, Connor JH (2010) Inhibition of heat-shock protein 90 reduces Ebola virus replication. Antiviral Res 87:187-194 
82. Csermely P, Schnaider T, Soti C, Prohaszka Z, Narda G (1998) The 90-kDa molecular chaperone family: structure, function, and clinical applications. A comprehensive review. Pharmacol Ther 79:129-168

83. Nascimento R, Costa H, Parkhouse RM (2012) Virus manipulation of cell cycle. Protoplasma 249:519-528

84. Thaker SK, Ch'ng J, Christofk HR (2019) Viral hijacking of cellular metabolism. BMC Biol 17:59

85. Verdonck S, Nemegeer J, Vandenabeele P, Maelfait J (2022) Viral manipulation of host cell necroptosis and pyroptosis. Trends Microbiol. In press

86. Wu W, Luo X, Ren M (2022) Clearance or Hijack: Universal interplay mechanisms between viruses and host autophagy from plants to animals. Front Cell Infect Microbiol 11:786348

\section{Figures}



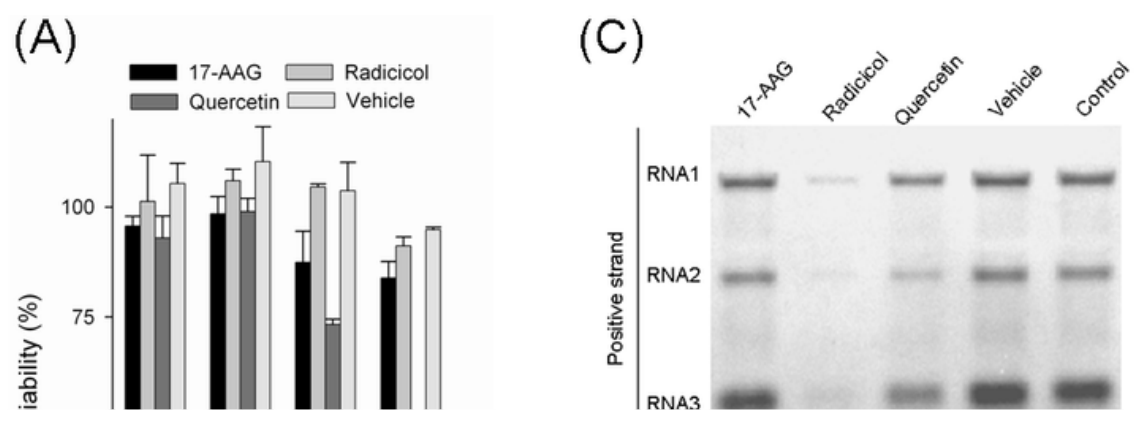

\section{Figure 1}

\section{Effect of the HSP inhibitors on virus multiplication.}

OLHNI-2 cells were incubated with $5 \mathrm{mM}$ radiciocl, $5 \mathrm{mM}$ 17-AAG, or $20 \mathrm{mM}$ quercetin after inoculation with RGNNV (MOI =1) for 30 min. Cells incubated with DMSO only were indicated as "vehicle". Cells incubated with normal culturing medium were used as the control. (A) The cytotoxic effects of the inhibitors were assessed by the WST-1 assay. The relative cell viability against the control was shown. (B) The production of progeny virus in the culture supernatants was determined by the $\mathrm{TCID}_{50}$ method at $12 \mathrm{~h}$ post virus inoculation. The numbers above the bars indicate the relative viral titers against the control cells. (C) Northern blot analysis of the viral 
RNAs and Western blot analysis of the coat protein were performed at $12 \mathrm{~h}$ post inoculation with RGNNV. Representative data are shown here. Positions of RNA1, RNA2, and RNA3 are indicated to the right. Expression of $\beta$-actin was detected as the loading control. (D) Quantitative analysis of the Northern blot and Western blot images in Fig. 1C. The relative expression was calculated against the control cells after normalization with the $\beta$ actin expression. Data are shown as mean values of three independent experiments with standard deviation.

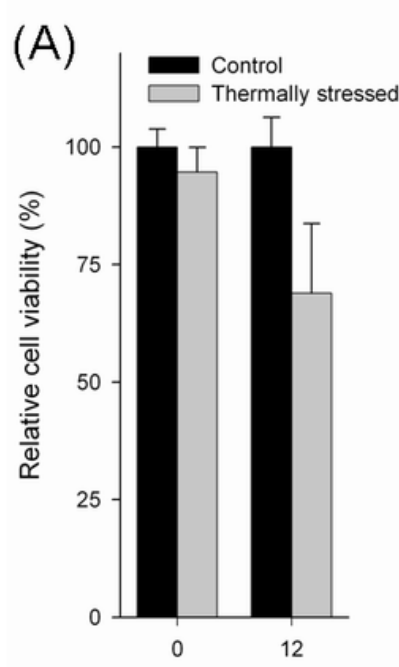

Hours post-thermal stress
(B)

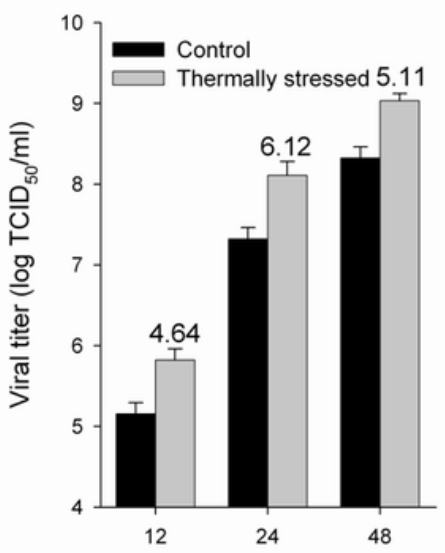

Hours post-inoculation
(C)

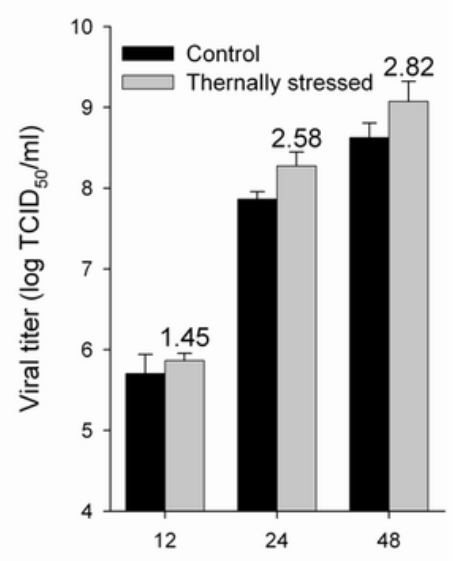

Hours post-inoculation

Figure 2 
Effect of the thermal stress on virus multiplication.

OLHNI-2 cells were thermally stressed at $42^{\circ} \mathrm{C}$ for $1 \mathrm{~h}$, and recovered at $30^{\circ} \mathrm{C}$ for $1 \mathrm{~h}$ (designated as $0 \mathrm{~h}$ post thermal stress). Cells continuously incubated $30^{\circ} \mathrm{C}$ was used as the control. (A) The cytotoxic effect of the thermal stress was assessed by the WST-1 assay. The relative cell viability against the control was shown. Thermally stressed cells then were inoculated with RGNNV (MOI=1) for $1 \mathrm{~h}$ at $0(\mathrm{~B})$, or $12 \mathrm{~h}(\mathrm{C})$ post thermal stress. The progeny virus in the culture supernatants was determined by the $\operatorname{TCID}_{50}$ method at $48 \mathrm{~h}$ post virus inoculation. The numbers above the bars indicate the relative viral titers against the control. (D) Northern blot analysis of the viral RNAs and Western blot analysis of the coat protein were performed at $12 \mathrm{~h}$ post inoculation with RGNNV. Representative data are shown here. Positions of RNA1, RNA2, and RNA3 are indicated to the left. Expression of $\beta$-actin was detected as the loading control. (E) Quantitative analysis of the Northern blot and Western blot images in Fig. 2D. The relative expression was calculated against the control cells after normalization with the $\beta$-actin expression.

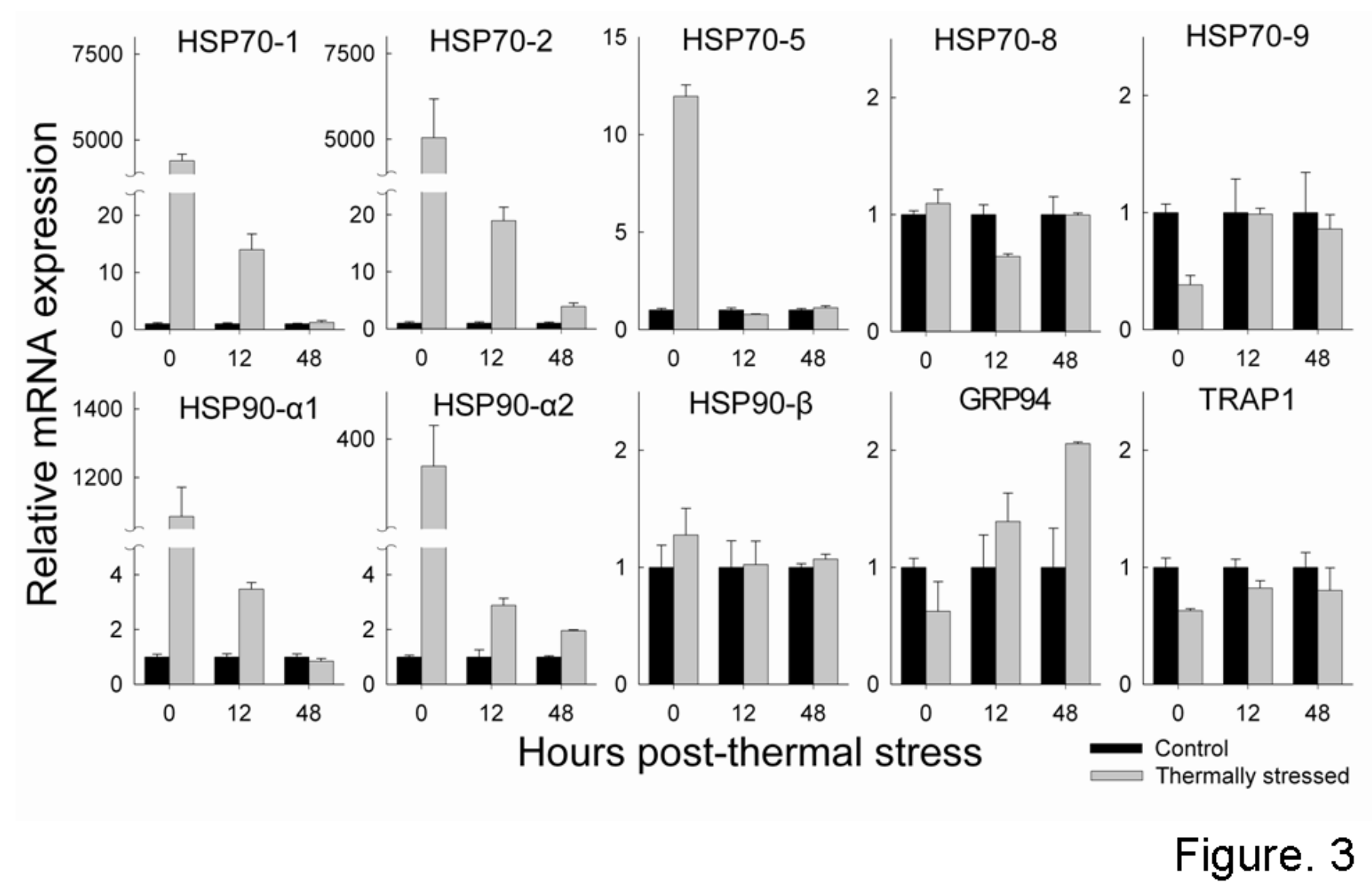

Figure 3

Effect of the thermal stress on the expression of the HSP70 and HSP90 isoforms.

OLHNI-2 cells were thermally stressed at $42^{\circ} \mathrm{C}$ for $1 \mathrm{~h}$ and recovered at $30^{\circ} \mathrm{C}$ for $1 \mathrm{~h}$ (designated as $0 \mathrm{~h}$ post thermal stress). Cells continuously incubated $30^{\circ} \mathrm{C}$ was used as the control. Total RNA was isolated from cells at 
0,12 , and $48 \mathrm{~h}$ post thermal stress and subjected to the quantitative real time RT-PCR analysis. The relative mRNA expression was calculated against the control after normalization with $\beta$-actin expression.

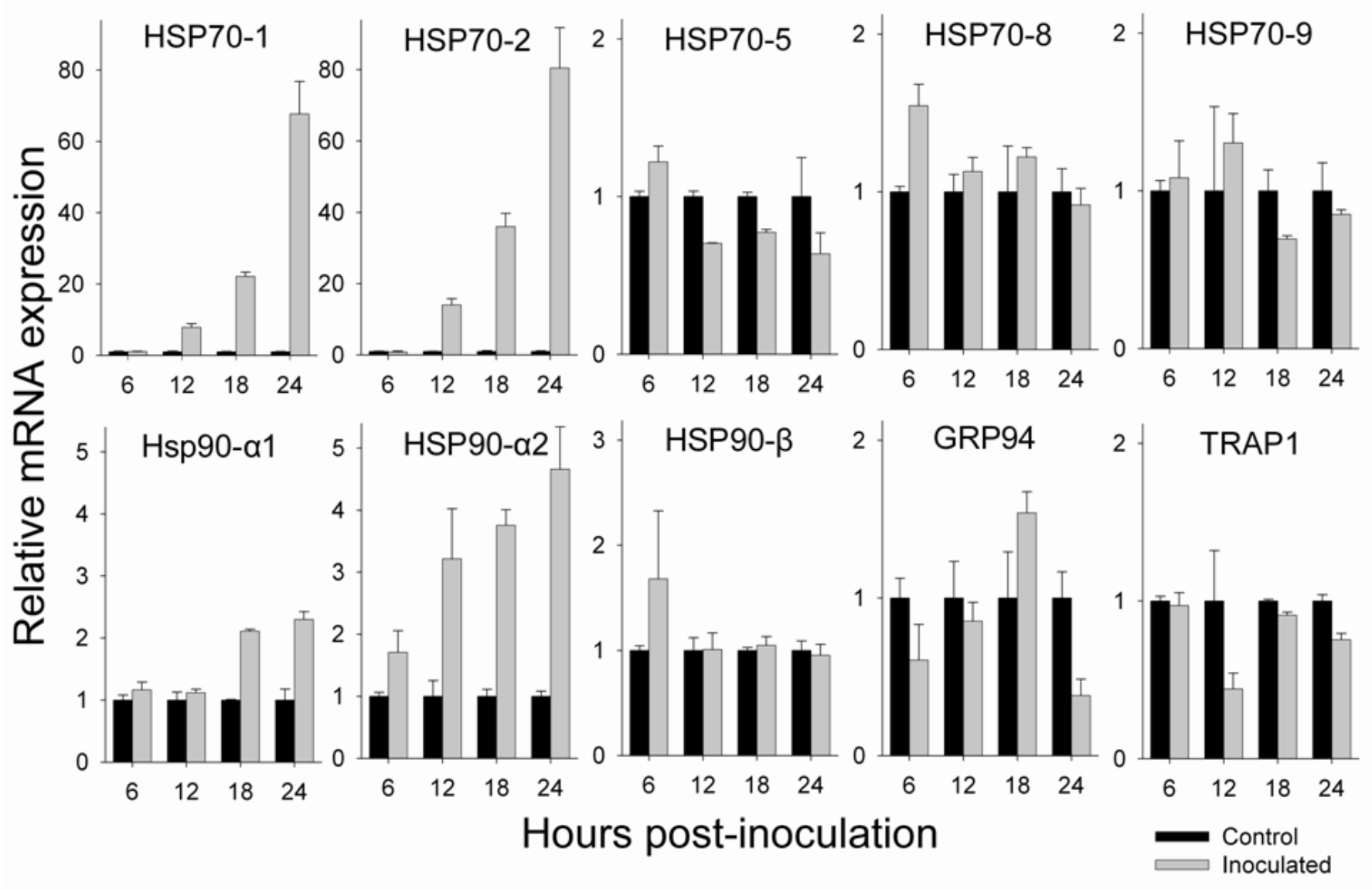

Figure. 4

Figure 4

Effect of the virus infection on the expression of the HSP70 and HSP90 isoforms.

OLHNI-2 cells were inoculated with RGNNV (MOI=1) for $1 \mathrm{~h}$. Cells without virus inoculation were used as the control. Total RNA was isolated from cells at $6,12,18$, and $24 \mathrm{~h}$ post inoculation and subjected to the quantitative real time RT-PCR analysis. The relative mRNA expression was calculated against the control after normalization with $\beta$-actin expression. 


\section{Figure 5}

\section{Effects of overexpression of the HSP isoforms on virus multiplication.}

OLHNI-2 cells were transfected with the expression plasmid vector encoding each of the HSP70 and HSP90 isoforms. Cells transfected with the expression vector encoding EGFP was used as the control. Cells then were inoculated with RGNNV (MOI=10) at $48 \mathrm{~h}$ after transfection. (A) Cells expressing each of the HA-tagged HSP70 and HSP90 isoforms were detected by immunocytochemistry at $48 \mathrm{~h}$ after transfection. The red fluorescence images of HSP-expressing cells were merged with the blue fluorescence images of DAPI-stained nuclei. Representative data from three independent experiments are shown here. The green fluorescence micrograph indicates the expression of EGFP in the control cells. (B) The viral titers in the culture supernatants were determined by the $\mathrm{TCID}_{50}$ method at $48 \mathrm{~h}$ post virus inoculation. The numbers above the bars indicate the 
relative viral titers against the control. Data are shown as mean values of three independent experiments with standard deviation.
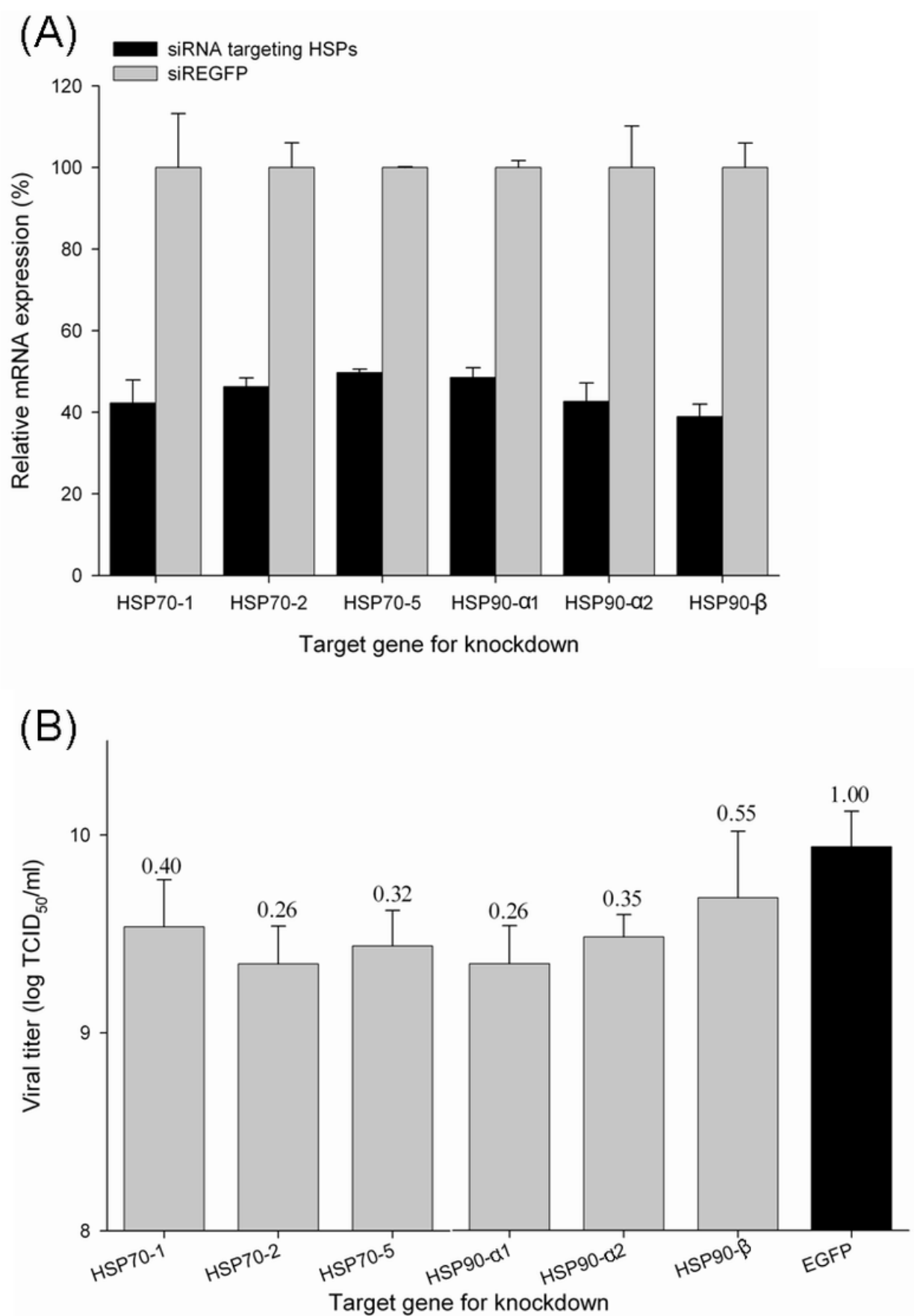

Figure. 6

\section{Figure 6}

\section{Knock down effects of the HSP isoform genes on virus multiplication.}

OLHNI-2 cells were transfected with the siRNA targeting each of the HSP70 and HSP90 isoforms. Cells transfected with the siRNA targeting EGFP (siREGFP) were used as the control. Cells then were inoculated with RGNNV (MOI=1) at $48 \mathrm{~h}$ after transfection. (A) The knockdown efficiencies of the siRNAs were assessed by the 
relative mRNA expression of the isoforms. Total RNA was isolated from cells at $48 \mathrm{~h}$ post transfection and subjected to the quantitative real time RT-PCR analysis. The relative mRNA expression was calculated against the control after normalization with $\beta$-actin expression. (B) The progeny virus in the culture supernatants was titered by the $\mathrm{TCID}_{50}$ method at $48 \mathrm{~h}$ post virus inoculation. The numbers above the bars indicate the relative viral titers against the control. 